\title{
The Role of Yoga in Bronchial Asthma
}

\author{
Saurabh Karmakar ${ }^{1 *}$, and Shilpi Karmakar ${ }^{2}$ \\ ${ }^{1}$ Department of Pulmonary Medicine, Era's Lucknow Medical College \& Hospital, India
}

${ }^{2}$ Department of Plastic Surgery, King George's Medical University, India

Submission: September 7, 2017; Published: August 22, 2018

*Corresponding author: Saurabh Karmakar, Assistant Professor, Department of Pulmonary Medicine, Era's Lucknow Medical College \&Hospital, Lucknow, UP, India; Email: doc_next_door@yahoo.com

Keywords: Yoga; Bronchial Asthma; Clinical manifestations; Optimum therapy; Therapeutic benefits; Flight-or-fight stress; Hypothalamicpituitary-adrenal

\section{Introduction}

Asthma is a heterogeneous disease comprising of clinical manifestations of varying severity. Patients of asthma suffer from progressive and persistent decline in lung function throughout life, the degree of decline varying among individuals.

Asthma affects 334 million people worldwide and 17 million people in India [1]. Majority of asthma patients are effectively treated with conventional therapy. Despite advances in conventional therapy, inadequate control of asthma continues to presenta serious problem for a subset of patients. Patients of uncontrolled asthma pose a greater burden for healthcare and require a disproportionate amount of healthcare costs to be spent on treating their condition. Optimum therapy for uncontrolled asthma remains an unmet need.

Although majority of patients respond well to low-dose controller medications such as inhaled corticosteroids and longacting $\beta$-agonists, a subset of patients remains uncontrolled despite the use of high-dose multiple-drug daily controller therapy. These patients experience substantial morbidity due to the disease and to the adverse effects of high-dose corticosteroids and generate high healthcare costs [2-5].

Yoga is a non-pharmacological adjunct to conventional therapy for asthma. The word "yoga" comes from the Sanskrit root yuj, which means union or yoke; to join and to direct and concentrate one's attention [6]. Yoga is an ancient art form based on a harmonised system of development of the body, mind, and spirit [7]. Yoga has been classified by National Institute of Health, USA as a form of Complementary and Alternative Medicine.

It is estimated that up to 300 million people practice yoga worldwide and more than half of them are Indians [8]. National Health Interview Survey last conducted in United States of
America in 2007 estimated that yoga is the sixth most common complementary health practice among adultsand more than 32 million people practice it in the country [9]. The participation and awareness in Yoga continues to increase in society, hence it is important for clinicians to know about the nature of Yoga and its therapeutic benefits.

Four basic principles underlie the teachings and practices of yoga. The first principle is the human body is a holistic entity comprised of various interrelated dimensions inseparable from one another and the health or illness of any one dimension affects the other dimensions. The second principle is individuals and their needs are unique and therefore must be approached in a way that acknowledges this individuality and their practice must be tailored accordingly. The third principle is, yoga is selfempowering; the healing comes from within, instead of from an outside source and a greater sense of autonomy is achieved. The fourth principle is that the quality and state of an individual's mind is crucial to healing [10].

Regular practice of yoga promotes strength, endurance, flexibility and facilitates characteristics of friendliness, compassion, and greater self-control, while cultivating a sense of calmness and well-being $[11,12]$. The practice of yoga produces a physiological state opposite to that of the flight-or-fight stress response and with that interruption in the stress response, a sense of balance between the mind and body is achieved [13]. Psychological factors like stress can modulate asthma symptoms and influence the management of asthma [14]. At the individual level, increased stress leads to the dysregulation of the hypothalamic-pituitary-adrenal and sympathetic-adrenalmedullary axes, disrupting immune and respiratory processes, and producing an increased risk of inflammatory diseases, such as asthma [15]. Yoga offers an effective method of managing and 
reducing stress. Yoga integrates an individual's physical, mental and spiritual componentsand produces a physiological sequence of events in the body reducing this stress response. Yogic practices enhance muscular strength and body flexibility, promote and improve respiratory and cardiovascular functionand enhance overall well-being and quality of life.

Asthma has many contributing factors, including exercise, allergy, air pollution, emotional factors and genetics. A multifaceted approach should be considered for its preventionand treatment. Yoga is a complementary therapy, helpful for asthma [16]. With its focus on awareness of breath and the mechanics of breathing, yoga serves as an adjunct to conventional asthma therapy [17]. Yoga is fundamentally different from conventional medical practice in its approach to asthma. Instead of trying to reduce the cause of disease to a single factor and to correct it, yoga aims to treat illness by improving health of the individual and restore inner harmony.

A study conducted by the Natural Therapies Unit of Royal Hospital for Women in Sydney, Australia showed a significant beneficial effect of SahajaYoga on asthma patients who were resistant to steroids [18].

Yoga practice should complement medicaltreatmentas prescribed by the physician. Regular yoga practice that combines pranayama, asana and meditation methods offer the most benefit [19].

\section{Specific Pranayama Exercises}

A vital scientific and therapeutic aspect of yoga, Pranayama is thebreathing process or the control of the motion of inhalation, exhalation and the retention of vitalenergy.

Ujayyi (breathing): The name comes from the Sanskrit word "ujayyi," which means "to conquer" or "to be victorious. The lungs are completely filled by inspiration and while slightly contracting the throat, breathing out is done through nose. This breathing technique is used throughout Ashtanga and Vinyasa yoga practices.

AnulomaViloma (three-part breathing): This threepart breath slows breathing by creating small pauses between the breath cycles. Payingattention to the movements of the belly, lower ribs and upper ribs can be helpful. During an asthmaepisode, this method may be more beneficial ifdone with very brief pauses during inhalation, toencourage maximal entry of oxygen and long, slow uninterrupted exhalation.

Extended exhalations: Initially the duration of inhalation and exhalation should be equal. Then aim for a 1:2 ratio ofinhalation and exhalation.

Alternate nostril breathing: This technique slows down person's breathing, and it is believed to balance the sympathetic and parasympathetic nervous system.

Yoga chair breathing: The patient sits on a chair facing the back ofanother chair and places his arms on the back of the chair he's facing. He inhales while gradually lifting thehead and spine and opening the chest, and then exhales while moving the spine, chest, and neck into gentleflexion, which is done five times.

Kapalabhati: The word kapalbhati is made up of two words: kapalmeaning "skull" and bhati meaning "shining". The technique involves short and strong forceful exhalations and inhalation happens spontaneously.

\section{Specific Asanas}

The concept of using asanas is to alter one's physical posture to increase breathing potential and breathe better. Asanas are isometric exercises that involve acoordinated action of synergistic and antagonist musclesin bringing about steadiness and flexibility. A gentle and progressive asana practice will allow the patient to increase lung capacity and strengthen intercostal muscles and muscles of back and diaphragm in preparation for pranayama [20].

Headstand (Sirshasana): It is the most important among inverted asanas. It is usually done at the end of the yoga asana practices.

Shoulderstand (Sarvangasana): It is an inverted pose, with the body resting on the shoulders.

Plough (Halasana): Hala Asanapromotes strength and flexibility in all the regions of the back and neck.

Fish (Matsyasana): The pose opens the rib case, deepens the breath and reverses kyphosis.

Sitting Forward Bend (Paschimothanasana): This pose uses gravity to calm and soothe the nervous system.

Cobra (Bhujangasana): This pose promotes thoraco diaphtagmaticbreathing, stretches the chest, strengthens the upper back and shoulders, and diminishes kyphosis.

Locust (Shalabhasana): Shalabhasana strengthens back muscles and cures ailments like sciatica and back ache.

Bow (Dhanurasana): It tones back muscles and maintains the elasticity of spine, improving posture and increasing vitality.

Spinal twist (ArdhaMatsyendrasana): ArdhaMatsyendrāsana tones the spinal nerves and ligaments, improves digestion and also improves liver and pancreas health.

Crow (Kakasana): Kakasana is a balancing posture which strengthens the shoulders, arms and wrists.

Standing forward bend (Padahastasana): It is an inverted posture which provides many of the same benefits of the seated forward bend, the main physical benefit is to stretch the entire backside of the body from the head to the heels.

Triangle (Trikonasana): Trikonasana (triangle pose) augments the movement of the Half Spinal Twist and gives an excellent lateral stretch to the spine, toning the spinal nerves and helping the proper functioning of the digestive system. 


\section{Meditation}

United States National Center for Complementary and Alternative Medicine (NCCAM) defines meditation as "a conscious mental process that induces a set of integrated physiological changes termed the relaxation response.

Asthma flares is associated with anxiety and pain. The body's sympathetic nervous system, responsible for its "fight or flight" response, goes into overdrive at the onset of an asthma flare, and releases stress hormones into the body. Meditation lowers stress hormone levels and decreases activity in the body's sympathetic nervous system. Medictation relaxes the mind and increases mental alertness [21]. The controlled breathing regime practiced as part of the meditation process is extremely beneficial for the lungs. Meditation opens air passages and improves airflow. With practice, one can learn to relax the body and breathe deeply early during the onset of an asthma attack; at the same time, focusing on the breathing freely will calm the mind and prevent anxiety or panic to take control.
Wilson et al did a crossover study to evaluate the benefits of Transcendental meditation on asthma. The results indicated that transcendental meditation is a useful adjunct in treating asthma [22]. In the Indian scenario, study by Biju et al showed that yoga resulted in significant improvement in pulmonary function tests, decrease in frequency of asthma attacks and decrease in frequency of use of inhalers whereas the disease status in controls deteriorated [23]. Yoga improves the mechanical efficiency of our breathing and increases the total lung capacity [24].

Thus, we see, Yoga contains elements that address problems associated with asthma at every level - pranayama that slows breathing and regulates the flow of "prana", asana that relax and tone the muscles, relaxation and meditation that act to calm the mind and emotions culturing to heal the spirit. Treatment of asthma is continually evolving. Multidisciplinary collaboration by bringing together researchers and clinicians should be the way forward in endeavours to provide effective solutions to help patients (Table 1).

Table 1: Common forms of Yoga [21].

\begin{tabular}{|c|c|}
\hline Hatha & $\begin{array}{c}\text { General term for yoga incorporating postures, as opposed to breathing or medication techniques. It's a basic, beginner style } \\
\text { with less challenging postures. }\end{array}$ \\
\hline Vinyasa & Fluid, flowing style wherein students move continuously between postures with co-ordinate breathing. \\
\hline Iyengar & Style known for emphasis on props to maintain proper body alignment even in less flexible students. Accessible to anyone. \\
\hline Astanga & $\begin{array}{l}\text { Vigorous school of yoga where students move rapidly and smoothly from one posture to next. Recommended for more athletic } \\
\text { students }\end{array}$ \\
\hline Bikram & Practiced in a room heated to over 100 degree Fahrenheit. Best for physically able practitioners (als known as "hot" yoga) \\
\hline Viniyoga & Incorporates breathing and chanting exercises. Postures are gentle and can be done by less fit students. \\
\hline Kundalini & Flowing style of yoga with emphasis on breathing techniques. May have more spiritual aspects than other styles. \\
\hline Kripalu & $\begin{array}{c}\text { Incorporates emotional and spiritual aspects similar to psychotherapy. Breathing and postures are combined, which can be } \\
\text { physically challenging }\end{array}$ \\
\hline Anusara & Emphasis on alignment, similar to Iyengar. Also incorporates chanting and breathing exercises. \\
\hline $\begin{array}{l}\text { Sudarshan } \\
\text { Kriya }\end{array}$ & $\begin{array}{c}\text { A series of breathing techniques with differing rates and levels of airway resistance that practitioners claim can balance the } \\
\text { autonomic nervous system. }\end{array}$ \\
\hline
\end{tabular}

Disclaimer: Please do not stop using asthma treatment without the advice of the specialist. Yoga should only be used to complement standard medical treatment.

\section{References}

1. Behera D, Sehgal IS (2015) Bronchial asthma - Issues for the developing world. Indian J Med Res 141(4): 380-382.

2. Chung KF, Wenzel SE, Brozek JL, et al. (2014) International ERS/ATS guidelines on definition, evaluation and treatmentof severe asthma. EurRespir J 43: 343-373.

3. Global Initiative for Asthma (2015) Global Strategy for Asthma Management and Prevention.

4. Hekking PP, Wener RR, Amelink M, Zwinderman AH, Bouvy ML, et al. (2015) The prevalence of severe refractory asthma. J Allergy ClinImmunol 135(4): 896-902.

5. Jarjour NN, Erzurum SC, Bleecker ER, Calhoun WJ, Castro M, et al. (2012) Severe asthma: lessons learned from the National Heart, Lung, and Blood Institute Severe Asthma Research Program. Am J Respir Crit Care Med 185(4): 356-362
6. Lasater J (1997) The heart of pantajali. Yoga J 137:134-44.

7. Woodyard C (2011) Exploring the therapeutic effects of yoga and its ability to increase quality of life. International Journal of Yoga 4(2): 4954.

8. https://www.rt.com/news/312015-india-yoga-asanas-patent/

9. http://yourstory.com/2015/06/international-yoga-day/

10. Desikachar K, Bragdon L, Bossart C (2005) The yoga of healing: Exploring yoga's holistic model for health and well-being. Int J Yoga Ther 15:17-39.

11. Collins C (1998) Yoga: Intuition, preventive medicine, and treatment. J Obstet Gynecol Neonatal Nurs 27(5): 563-568.

12. McCall T (2007) Yoga as Medicine. New York, NY: Bantam Dell, Random House, Inc.

13. Arora S, Bhattacharjee J (2008) Modulation of immune response in stress by yoga. Int J Yoga 1(2): 45-55. 
14. Karmakar S, Gupta N, Prasad R (2015) Stress and Asthma. Souvenir of 11 th National Seminar on Management of Mental Healththrough Yoga \& Naturopathy, p. 40-42.

15. Wright RJ, Cohen RT, Cohen S (2005) The impact of stress on the development andexpression of atopy. CurrOpin Allergy ClinImmunol 5(1): 23-29.

16. Perlman A, Scrbin JS (2001) Nontraditional approaches to asthma. Women's Health in Primary Care 4: 405-410.

17. Verrastro G (2014) Yoga as therapy: when is it helpful? J FamPract 63: E1-6.

18. Manocha R, Marks GB, Kenchington P, Peters D, Salome CM (2002) Sahaja yoga in the management of moderate to severe asthma: a randomised controlled trial. Thorax 57: 110-115.

19. Morse D (2007) Yoga for Asthma. International Journal of Yoga Therapy 17(1): 81-88.
20. Desikachar TVK (1999) Asana Variations. In: Desikachar TVK (Ed.), The Heart of Yoga: Developing a Personal Practice, 1st ed. Vermont: Inner Traditions International, p. 59.

21. Cabral P, Meyer HB, Ames D (2011) Effectiveness of Yoga Therapy as a Complementary Treatment for Major Psychiatric Disorders: A MetaAnalysis. The Primary Care Companion to CNS Disorders 13(4): 1-18.

22. Wilson AF, Honsberger R, Chiu JT, Novey HS (1975) Transcendental meditation and asthma. Respiration 32(1): 74-80.

23. B Biju, Geetha N, Sobhakumari T (2012) Yoga Training with Meditation Ameliorates the Asthmatic Attack by Improving Pulmonary Functions: A Pilot Study. Natl J Med Res 2(2): 182-187.

24. Krishnan S (2003) "Yoga - A Remedy to Respiratory Illness". In Bunch MJ, Suresh VM, Kumaran TV, (Eds), Proceedings of the Third International Conference on Environment and Health, ( $1^{\text {st }}$ edn). Chennai: Department of Geography, University of Madras and Faculty of Environmental Studies, York University Pp. 243-251.

\section{Your next submission with Juniper Publishers} will reach you the below assets

Commons Attribution 4.0 License

DOI: 10.19080/JCMAH.2018.07.555708
- Quality Editorial service

- Swift Peer Review

- Reprints availability

- E-prints Service

- Manuscript Podcast for convenient understanding

- Global attainment for your research

- Manuscript accessibility in different formats

( Pdf, E-pub, Full Text, Audio)

- Unceasing customer service

Track the below URL for one-step submission https://juniperpublishers.com/online-submission.php 